\title{
Early Detection of Drug Susceptibility Test for Mycobacterium Tuberculosis by Slide DST Method Using Two Media- Middle Brook 7H9 Broth and Human Blood Media
}

\author{
Amruta Patil $^{1}$, Dr. P. B. Desai ${ }^{2}$ \\ ${ }^{1,2}$ Shree Ramkrishna Institute of Computer Education and Applied Sciences, \\ Veer Narmad South Gujarat University, Surat-395 001, Gujarat, India
}

\begin{abstract}
This study was designed for early detection of drug resistance TB from direct sputum sample and also to suggest a simple method to detect multi drug resistance MTB. Samples were collected from 496 clinically suspected pulmonary tuberculosis cases. From that 207 samples were positive by smear microscopy. Culture and drug susceptibility were done by slide culture method using two media Middle brook 7H9 broth and Human blood media (HBM). From 207 samples 73 sample found to be MDR by Slide DST using Middle brook 7 H9 broth and 74 sample using HBM. Sensitivity of Slide DST method was $97 \%$ with human blood media and $96 \%$ in case of Middle brook $7 \mathrm{H}^{9}$ broth. Time taken for the result was much less than conventional method. Susceptibility results were available much faster by slide DST method (10 days) compared to that by conventional DST (60 days). Cost of Slide DST method(20 Rs. for HBM \& 45 Rs. for Middle brook $7 \mathrm{H} 9$ broth) for the detection was much lower than conventional DST. Slide DST method using these two medium could be applied as rapid diagnostic tool to detect drug resistance as it is very cheap and faster for diagnosis of drug resistance TB.
\end{abstract}

Keyword: Slide DST, Early detection, drug susceptibility, tuberculosis

\section{Introduction}

Mycobacterium tuberculosis cause the major air borne disease in human called TB. Due to drug resistance it is major health problem in the world. In the world every year 9.4 million new cases detected, From that 1.5 million patient were died from TB according to WHO 2015(1). In 201322 countries reported $80 \%$ cases of TB. From 8.6 million cases 2.2 million cases occurred in India making India the world's highest tuberculosis burden country(TB India 2014)(2). In world in 2013 there were $5 \%$ of TB cases estimated to have had MDR-TB ( $3.5 \%$ new cases and 20.5 of previously treated TB cases)(1). Globally Drug resistance data show that an estimated 480000 people develop MDR-TB in 2013 and 210000 people died. In 2013100 countries report XDR TB. On a average an estimated $9 \%$ of people with MDR-TB have XDR-TB. (1)

Multi drug resistance means Mycobacterium tuberculosis that are resistant to at least isoniazide and refampicin- which are most effective anti- TB drug. MDR-TB cause by primary infection or during drug treatment (3). MDR TB patient carry strain resistant to the most anti tuberculosis drug, so it is very difficult to treat. There is chance to develop extensive drug resistance Tuberculosis from MDR TB. (XDR-TB)(4)

For control of TB, early diagnosis is necessary. It is a mystery to diagnose mycobacterial infection (5). With the correct diagnosis and appropriate treatment disease can be cure (5). Solid egg based media like Lowenstein Jensen(LJ) and ogawa media used in most of developing countries for culture and susceptibility test due to low cost. Time taken by this method 3-8 week for culture and for susceptibility it takes further4-6 weeks. This is gold standard method, gives accurate result but take too much time.(6)

Bactec mycobacterial growth indicator tube (MIGT)- the fully automated commercial system gives rapid detection of resistance of first and second line drug within 10 days, but it require expensive equipment that are not easily available or suitable for resource limited countries \& Gene expert is one of the system which give the result of susceptibility within three hours, it is rapid but require more expensive instrument (7).

In liquid media Mycobacterium can grow more rapidly than solid media, where it grow as micro colony ,based on this observation, a new, efficient, reliable and inexpensive method known as slide DST, which gives the result for detection within 10 days.(8) This method has to have the following desirable features like results as early as possible, simple training, easy interpretation, and allow start of the treatment as early as possible.(9)

Robert Koch was the first to use rapid slide culture technique using coagulated human serum, he was successful in obtaining the growth of Mycobacterium bacilli in 7 days but contamination hindered further success.(10)

For early and rapid diagnosis of drug resistance TB as well as MDRTB/XDR TB in poor setting countries slide DST may be suitable system. Accurate TB diagnosis can be made by good contamination control and sufficient equipment in smear positive cases (11). There is need for improved technologies for rapid detection of drug resistance because of the emergence of MDR-TB and XDR-TB in TB.(12). The 


\section{International Journal of Science and Research (IJSR) \\ ISSN (Online): 2319-7064 \\ Index Copernicus Value (2013): 6.14 | Impact Factor (2014): 5.611}

objective of this study is early detection of drug resistance among TB patient and evolution of simple technique.

\section{Material and Methods}

A total of 495 clinical samples (sputum) were obtained from patients of suspected pulmonary TB from June 2013 to august 2015. The patient was asked to take early morning sputum. When he wakes up without brushing the teeth, asked to a deep breath and expectorates sputum in given wide mouthed sterile plastic container.

\subsection{Staining procedure}

Ziehlneelsen (ZN) staining was performed by standardize method.(13)

\subsection{Slide DST by middle brook 7 H9 broth}

This method is used for detection of drug susceptibility of Mycobacterium tuberculosis to isoniazide (INH) and rifampicin (RIF).For identification between MTB and NMTB paranitro benzoic was used. The study adapted the method described by hemid et al. using middle brook $7 \mathrm{H} 9$ broth -a liquid media with oleic acid albumin dextrose catalase as growth supplement and PANTA used as decontaminant $(0.1 \mathrm{ml} / 5 \mathrm{ml}$ media $)$ and anti-TB drugs. $7 \mathrm{ml}$ drug containing and $7 \mathrm{ml}$ drug free media were poured in two different sterile heavy MCcartney bottle. For each sample 5 sputum smear were made direct from sputum sample on one end of autoclaved slide which cut in half longitudinally, and dip into bottle containing drug isoniazied $0.2 \mu \mathrm{g} / \mathrm{ml}$, rifampicin $1 \mu \mathrm{g} / \mathrm{ml}$ concentration and in three drug free bottles. All bottles were incubated at $37 \mathrm{c}$ for 10 days. After 10 days bottles were removed from incubator and with the help of the forcep slides from bottles were removed and put it on the brown paper which absorbed 0excess medium and air dried the slide. slides were heat fixed on the hot plate at $80 \mathrm{c}$ for $30 \mathrm{~min}$. Then slides were subjected to $\mathrm{ZN}$ staining and examined for acid fast microcolonies at 100x magnification. Any number of well developed colonies with cording in presence of drug was interpreted as resistance.

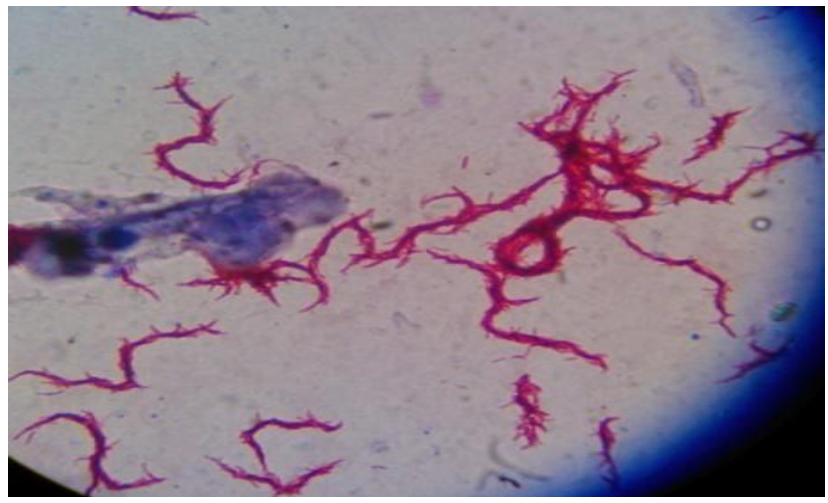

Figure 1: Microcolonies of M.tuberculosis showing cord formation at 100x magnification under Bright Field Microscope.

\subsection{Slide DST by human blood media}

For preparing the media, out dated but not more than 4 week old citrated human blood was used with an equal volume sterile deionized water this blood was diluted to cause hemolysis. the media was made selective by adding polymixin-B $(2,00,000$ unit/l) , carbenicillin $(100 \mathrm{mg} / \mathrm{l})$ ,trimethoprim $(10 \mathrm{mg} / \mathrm{l})$ and amphotericin-B $(10 \mathrm{mg} / \mathrm{l})$ and adjusted the $\mathrm{pH}$ between 6.5 to 7.5. For each sputum sample 3 drug free media and 2 drug containing bottle 1 of $0.2 \mu \mathrm{g} / \mathrm{ml}$ isoniazide and 1 of $1 \mu \mathrm{g} / \mathrm{ml}$ rifampicin were prepared . For each sputum sample 5 sputum smear were made directly from sputum sample on the one end of the sterile autoclaved glass slide which was cut in half longitudinally. slides were dipped in drug free and drug containing medium containing MCcartnry bottle. After 10 days slides were removed from bottle and dipped in sterile distilled water to remove excess blood for $5 \mathrm{~min}$. After washing slides were air dried and heat fixed on hot plate for $30 \mathrm{~min}$ at $80 \mathrm{c}$. $\mathrm{ZN}$ staining was performed and examined under 100x for microcolonies. Any number of well develop colonies with cording in the presence of drug was interpreted as resistance. The growth was recorded as follows

\begin{tabular}{|c|c|}
\hline 0 & No division of AFB as compared to Control slide \\
\hline $1+$ & $\begin{array}{c}\text { Small clumps of up to } 4 \text { bacilli provided these were not } \\
\text { present in control slide }\end{array}$ \\
\hline $2+$ & Large clumps of bacilli \\
\hline $3+$ & Large clumps with some cord formation \\
\hline $4+$ & Micro colonies with good cord \\
\hline
\end{tabular}

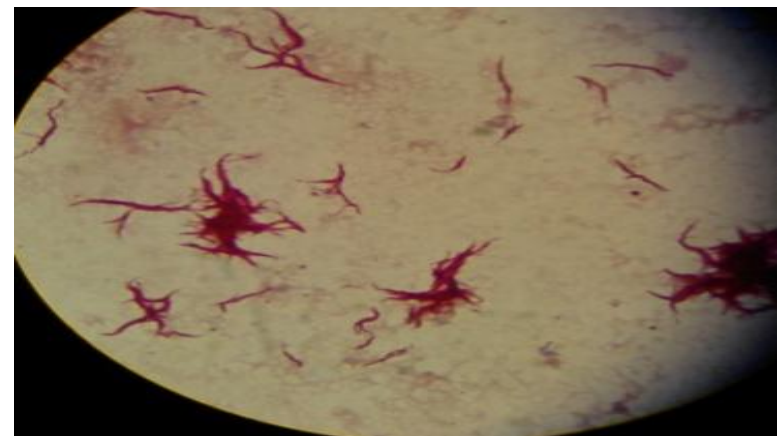

Figure 2: Microcolonies of M.tuberculosis showing cord formation at 100x magnification under Bright Field Microscope.

\section{Result}

From 496 suspected pulmonary TB sample 207 samples were found positive by smear microscopy. All Smear positive samples saw culture positive by Slide DST and LJ method.

Table 1: comparison of conventional method with smear microscopy and slide DST methods for positiveTB

\begin{tabular}{|c|c|c|c|}
\hline $\begin{array}{c}\text { Method for } \\
\text { diagnosis }\end{array}$ & $\begin{array}{c}\text { Total } \\
\text { samples }\end{array}$ & $\begin{array}{c}\text { No.of Positive } \\
\text { Cases }\end{array}$ & $\begin{array}{c}\% \text { of positive } \\
\text { cases }\end{array}$ \\
\hline Smear microscopy & 496 & 207 & 41.73 \\
\hline LJ & 496 & 207 & 41.73 \\
\hline Slide DST & 496 & 207 & 41.73 \\
\hline
\end{tabular}

By Slide DST method 37 cases were mono resistsnce and 74 cases were multi drug resistence.( Table 2) 


\section{International Journal of Science and Research (IJSR) \\ ISSN (Online): 2319-7064}

Index Copernicus Value (2013): 6.14 | Impact Factor (2014): 5.611

Table 2: Result of drug resistance by Slide DST method

\begin{tabular}{|c|c|c|c|}
\hline $\begin{array}{c}\text { Resistance } \\
\text { pattern }\end{array}$ & $\begin{array}{c}\text { Anti-TB } \\
\text { drug }\end{array}$ & $\begin{array}{c}\text { Slide DST } \\
\text { by HBM }\end{array}$ & $\begin{array}{c}\text { Slide DST by 7H9 } \\
\text { broth }\end{array}$ \\
\hline Mono & INH & 20 & 20 \\
\hline & RMP & 17 & 16 \\
\hline Multi & INH+RMP & 74 & 73 \\
\hline Susceptible & & 96 & 98 \\
\hline Total & & 207 & 207 \\
\hline
\end{tabular}

Statically analysis shows Sensitivity of Slide DST using HBM have $97 \%$ and $96 \%$ by Middle brook 7 H9. Time taken for the result was much less then proportion method.(Table3)

Table 3: Comparison of time required for diagnosis of Drug resistance $\mathrm{TB}$

\begin{tabular}{|l|l|}
\hline Methods for diagnosis & Time taken for the result \\
\hline Conventional Method & 60 days \\
\hline Slide DST by HBM & 10 days \\
\hline Slide DST by Middle brook 7H9 & 10 days \\
\hline
\end{tabular}

Table 4: comparision of cost of methods for diagnosis of drug resistance $\mathrm{TB}$

\begin{tabular}{|c|c|}
\hline Methods for diagnosis & Cost (Rs.) \\
\hline Conventional LJ & 250 \\
\hline Slide DST by HBM & 20 \\
\hline Slide DST by Middlebrook 7H9 & 45 \\
\hline
\end{tabular}

\section{Discussion}

Early drug susceptibility test is important in tuberculosis patient. Because of there are chance of treatment failure patient it is more important. In india DST is done on solid media because it is low cost and it takes 2-3 month time. Present study was designed to rapid detection of drug resistances direct from sputum sample which are smear positive and introduce a simple and rapid method.

In Slide DST, $47 \%$ cases were found to have resistance against Isoniazide drug and $45 \%$ against rifampicin drug. Total 74 cases were found to have drug resistance against isoniazid and rifampicin (MDR) from 207 smear positive cases. Fahmida et al 2011 author found $80 \%$ cases were detected as MDR TB in category 2 failure patient (14), Kamal et al 2009 and Rahman et al 2009 found 83\% and $87 \%$ MDRTB respectively among category 2 failure patient by (15-16). The probable causes of above finding may be due to treatment with an inadequate drug regimen or re infection while under treatment(17). By this study the sensitivity of slide DST method was $97 \%$ using HBM and $96 \%$ using middlebrook $7 \mathrm{H} 9$ broth. by Fahmida et al 2011 found sensitivity of slide DST was $98.8 \%(14)$. Hamid Slim et al 2006 found $100 \%$ sensitivity and $62 \%$ specificity (11).

7 bottles were contaminated in slide DST by middle brook 7 H9 broth and 10 bottles were contaminated in Human blood media. rate of contamination was $1.4 \%$ and $2 \%$ in middle brook $7 \mathrm{H} 9$ broth and Human blood media respectively. Tortoliet al.,found $11 \%$ contamination in their study by conventional method,(18).one author found $0.18 \%$ contamination in slide DST method. Hamid et al. was found $7.4 \%$ contamination by slide DST in their study (11). Rate of contamination is lower than conventional method .Possible explanation of these authors findings are these of penicillin instead of PANTA or MAST tablet.

Drug susceptibility detection time by slide DST method in the present study was 10 days, and it correlates with other studies - 10 days by Hamid et al11, 8 days by Dickinson etal.10 Whereas, detection time by conventional DST was $60.4 \pm 5.9$ days(14). Accordingly, slide DST provides good opportunity for rapid identification of MDR strain. This early information is of great advantage in clinical settings to choose an appropriate drug regimen.

There are many limitation of slide DST although it is cheaper than automated culture method, it require costly media, growth and antibiotic supplement, which are not commonly available in field level laboratories in developing countries. Only microscopically positive sputum sample could be tested. As control strains cannot be used so its quality assurance is also a challenge. Slide DST is qualitative tests in which the observer confirms resistance by visualizing growth under microscope; where any well developed micro colony in presence of drug interprets as resistance to that drug. In slide DST there are no discrete colonies to count and a proportion cannot be calculated. As a result slide DST might over diagnose resistance, that is, isolates read as susceptible by reference method. Slide DST can provide good opportunity for rapid

Slide DST can provide good opportunity for rapid detection of drug resistance TB including MDR/XDR strain from direct sample within 10 days. This method can be implemented as rapid diagnostic tool to detect drug resistance tuberculosis.

\section{References}

[1] WHO Globle tuberculosis control report 2015

[2] Revised National TB Control Programme. TB india 2014, RNTCP annual status report.

[3] Multidrug and extensively drug-resistant TB (M/XDRTB): 2010 global report on surveillance and response,pp- 6

[4] Caminero JA. Multidrug-resistant tuberculosis: epidemiology, risk factors and case finding. Int J Tuberc Lung Dis 2010 14(4):382-390

[5] Negi, S.S., Khan, S.F.B., Gupta, S, 2005.Comparison of the conventionaldiagnostic modalities, BATEC culture andpolymerase chain reaction test fordiagnosis of tuberculosis. Indian J. Med.Microbiol., 23(1): 2933

[6] Kent BD \&Kubica GP. Public health microbiology, Aguide for the level III laboratory, U.S. Department of Health and Human services, Center for disease control, Atlanta, Ga.1985; pp. 36-39, 47-69, and 185-18

[7] Katoch VM. Newer diagnostic techniques for tuberculosis. Indian J Med Res 2004; 120:418-28

[8] Dickinson JM, Allen B W, Mitchison DA. Slide culture sensitivity tests. Tubercle 1989;70: 115-121

[9] Ramachandran, R., Paramasivan, C.N. 2003. What is new in the diagnosis oftuberculosis? Part 1: Techniques for diagnosis of Tuberculosis. Indian J.Tuberculosis, 50: 133141

\section{Volume 5 Issue 2, February 2016}




\section{International Journal of Science and Research (IJSR) \\ ISSN (Online): 2319-7064}

Index Copernicus Value (2013): 6.14 | Impact Factor (2014): 5.611

[10]Koch, R, Uber die Aeliologic der Tuberkulose, Bed. Klin. Wschnschr in Berry JW and Lowry Hope DH: A slide culture method for the early detection and observation of growth of the tubercle bacillus. Am. Rev. Tuberc. 1949, 60, 51.

[11] Hamid Salim A, Aung KJ, Hossain MA, Van Deun A. Early and rapid microscopy-based diagnosis of true treatment failure and MDR-TB. Int J Tuberc Lung Dis 2006; 10(11); 1248-1254

[12] Anti-tuberculosis drug resistance in the world. Reportno.4.WHO/HTM/TB/2008.394.Geneva,Switzerla nd

[13]Revised National Tuberculosis Control Programme (RNTCP). Manual forLaboratory Technicians. 1998. http://www.tbcindia.org/LABMANUAL.pdf. Accessed June 16, 2011

[14]Fahmida R, Md. Ruhul A Mi, Md. Mustafa K, Humayan S, Ahmed A S, Sharmeen A, Shirin T, Shaheda. A rapid Drug Susceptibility Test (DST) for detection of Multi-Drug Resistant (MDR) Mycobacteriumtuberculosis from direct sputum sample in Category II failure Tuberculosis patients in Bangladesh. J Med Microbiol 2011; 05 (02): 06-10

[15] Kamal SM , Shamim MD, Tauhidul AB M, Bleumink B, Van Deun A, Mujtaba A, Hiron M, Sarwar KM, Siddique JH, Rahman M. Anti-Tuberculosis Drug resistance Patterns among Category II failure patients in Bangladesh. Chest \& Heart Journal 2009; 33(2):118121.0

[16] Rahman M, Kamal SM, Rabbi F, Alam MD, Ahasan N. Anti tuberculosis drug resistance pattern among different category of tuberculosis patients. J Medicine 2009; 10:45-47.

[17] Matthys F, Rigouts L, Sizaire V, Vezhnina N, Lecoq M, Golubeva V, Portaels F, Vander P, Kimerling M. Outcomes after chemotherapy with Technicians. 1998. http://www.tbcindia.org/LABMANUAL.pdf. Accessed June 16, 2011

[18] WHO category II regimen in a population with high Prevalence of drug resistant tuberculosis.Plosone.www.plosone.org 2009; 4 (11) e7954.

[19] Tortoli E, Cichero P, Piersimoni C, Simonetti MT, Gesu G, Nista DUse of BACTEC MGIT 960 for recovery of mycobacteria from clinical specimens. J Clin Microbiol 1999; 37: 3578-3582.2 